\title{
The impact of sulfur on the transfer of platinum group elements by geological fluids.
}

\author{
CLÉMENT LASKAR ${ }^{1}$, MARIA A. KOKH ${ }^{1}$, ELENA F. \\ BAZARKINA $^{2}$, ELSA DESMAELE ${ }^{3}$, JEAN-LOUIS \\ HAZEMANN $^{2}$, RODOLPHE VUILLEUMIER ${ }^{3}$ AND GLEB S. \\ POKROVSKI $^{1}$ \\ ${ }^{1}$ Géosciences Environnement Toulouse - CNRS - Univ Toulouse \\ III - IRD - CNES - OMP \\ ${ }^{2}$ Institut Néel - CNRS \\ ${ }^{3}$ Ecole normale supérieure - CNRS \\ Presenting Author: clement.laskar@get.omp.eu
}

Knowledge of the speciation and solubility of platinum group elements (PGE) in magmatic-hydrothermal fluids is a key to interpret PGE geochemical transfers and ore deposit formation. PGE's are suggested to be transported as $\mathrm{Cl}^{-}$and $\mathrm{HS}^{-}$complexes [1-3]; however, these data predict too small metal contents in the fluids from S-rich geological settings, calling upon a possible role of the trisulfur ion $\left(\mathrm{S}_{3}{ }^{-}\right)$as a ligand for PGE transport [4]. Here we combined molecular dynamics (MD) and thermodynamic (TD) modeling, solubility measurements, and insitu X-ray absorption spectroscopy (XAS), to obtain a new coherent dataset to quantify the effect of sulfur on PGE mobility. Our calculations and experiments show that three main complexes transport $\mathrm{Pt}$ in the fluid over a wide $\mathrm{pH}$ range (4-8) at $300^{\circ} \mathrm{C}$ and 500 bar: $\mathrm{Pt}(\mathrm{HS})_{4}{ }^{2-}$ (Fig. 1A) and possibly $\mathrm{Pt}(\mathrm{HS})_{2}{ }^{0}$ in hydrogen sulfide $\mathrm{H}_{2} \mathrm{~S} / \mathrm{HS}^{-}$solutions, and $\mathrm{Pt}(\mathrm{HS})_{2}\left(\mathrm{~S}_{3}\right)_{2}{ }^{2-}$ (Fig. 1B) in sulfide-sulfate $\mathrm{H}_{2} \mathrm{~S} / \mathrm{SO}_{4}{ }^{2-} / \mathrm{S}_{3}{ }^{--}$solutions, in which $\mathrm{Pt}$ concentrations are as high as $10 \mathrm{~s}$ ppm. Furthermore, MD simulations were conducted to confirm the stability of these complexes, and ab-initio thermodynamic integration [6] was employed to predict, independently from our experiments, the stability of those complexes. Our approach integrates, for the first time, complementary cutting-edge techniques to highlight the important role of sulfur in the transport of PGE by aqueous fluids in the Earth's crust.

[1] Tagirov et al. (2019), GCA 254, 86-101.

[2] Bazarkina et al. (2014), GCA 146, 107-131.

[3] Filimonova et al. (2021), Chem. Geol. 559, 119968.

[4] Pokrovski et al. (2015), PNAS 112, 13484-13489.

[5] Pokrovski and Dubessy (2015), EPSL 411, 298-309.

[6] Mei et al. (2015), GCA 161, 128-145.

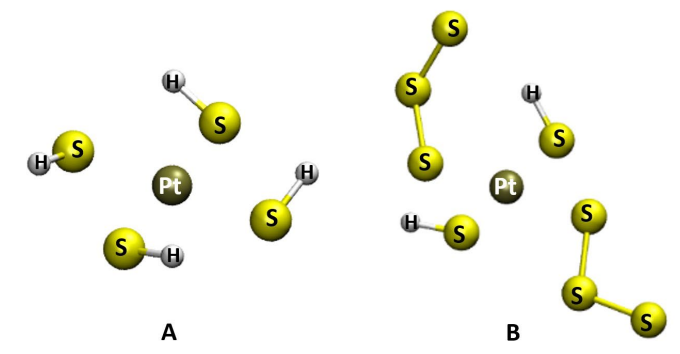

Fig. 1 